\title{
PENGARUH MOTIVASI DAN LINGKUNGAN KERJA TERHADAP KINERJA KARYAWAN
}

\author{
Firdaus \\ E - mail : ampuh53@gmail.com \\ Rahmi Widyanti \\ Khuzaini
}

Universitas Islam Kalimantan (UNISKA) MAB Banjarmasin

\begin{abstract}
This study aims to, prove significant influence motivation partially on employee performance, proving significant effect partially to the Work Environment Employee Performance, and prove the significant influence of Motivation and Work Environment simultaneously against South PT.Tanjung Employee Performance Makmur Jaya South Kalimantan.

Methods of analysis using multiple linear regression equation .Populasi in this study were all fixed karwayan South PT.Tanjung Makmur Jaya South Kalimantan .Sampel research as much as 67 .Pengujian partially Variables Influence Motivation (X1) the Employee Performance is equal to 17,182, thus, the hypothesis that motivation berpengauh positive and significant impact on Employee Performance South PT.Tanjung Makmur Jaya South Kalimantan proved acceptable. Working Environment Variables Influence (X2) to the environment variable $t$ value is equal to 9,785 , thus partially the environment has a significant impact on employee performance South PT.Tanjung Jaya Makmur South Kalimantan proved acceptable. Effect of Motivation and Work Environment Variables simultaneously towards employee performance with the result of 178,391 F count larger than $\mathrm{F}$ table 3,140, thus simultaneously Motivation and Work Environment positive and significant impact on Employee Performance PT. South Tanjung Jaya Makmur South Kalimantan proved acceptable.
\end{abstract}

Keywords: Motivation, Work Environment and Employee Performance. 


\section{PENDAHULUAN}

\section{Latar Belakang}

Perusahaan dalam menghadapi tekanan-tekanan perubahan dan persaingan dituntut untuk memberikan tanggapan agar perusahaan dapat tetap bertahan dan sukses dalam persaingan bisnis saat ini dan yang akan datang. Meningkatnya persaingan dunia bisnis mengharuskan perusahaan memeriksa ulang ukuran kinerja perusahaan mereka karena ukuranukuran kinerja yang ada dirasa semakin kurang efektif. "Kinerja yang dicari oleh perusahaan dari seseorang tergantung dari kemampuan, motivasi, dan dukungan individu yang diterima" (Mathis dan Jakson, 2006: 89). Apabila individu dalam perusahaan yaitu sumber daya manusianya dapat berjalan efektif maka perusahaan tetap berjalan efektif.

“Lingkungan kerja merupakan salah satu faktor yang mempengaruhi tercapainya kinerja yang optimal. Perusahaan harus mampu melakukan berbagai kegiatan dalam rangka menghadapi atau memenuhi tuntutan dan perubahan-perubahan di lingkungan perusahaan" (Rivai, 2004:307). Lingkungan kerja dapat menciptakan hubungan kerja yang saling mengikat dengan orangorang yang ada di dalam lingkungannya. Oleh sebab itu, sebaiknya diusahakan agar lingkungan kerja dapat tercipta dengan baik dan bisa kondusif sehingga dapat menjadikan karyawan menjadi merasa nyaman berada di ruangan dan merasa bersemangat untuk melaksanakan tugas-tugasnya sehingga terbentuk kepuasan kerja, lalu dari kepuasan kerja karyawan inilah maka kinerja karyawan juga akan meningkat.

“Perusahaan juga dapat menciptakan suasana kerja yang menyenangkan dalam artian ada hubungan baik antar karyawan, antara karyawan dengan atasan, serta menjaga kesehatan, keamanan di ruang kerja maka akan menimbulkan produktivitas kerja karyawan" (Ahyari, 2002:207). “Kesehatan fisik dan mental 
karyawan juga harus diperhatikan oleh perusahaan. karyawan dapat menjadi stres, terkena penyakit atau mengalami kecelakaan kerja jika kondisi lingkungan kerja kurang diperhatikan. Oleh karena itu gangguan-gangguan penglihatan, pendengaran, kelelahan serta lingkungan kerja berupa suhu dan kelembaban, sangat perlu dikendalikan atau diperkecil semaksimal mungkin" (Umar, 2004:18).

Lingkungan kerja Islami terdiri dari ritual atau atribut dan makna atau substansi dari,membentuk lingkungan kerja Islami harus dimulai dari diri sendiri, dari yang mudah dan dari sekarang. Cara yang dilakukan antara lain memberantas KKN, menumbuhkan etos kerja keras, meningkatkan profesionalitas, mengatur jadwal kerja sesuai dengan waktu ibadah, serta menyusun aturan/kebijakan sesuai dengan nilai-nilai Islam.

Objek dalam penelitian ini adalah PT Tanjung Selatan Makmur Jaya berlokasi di Desa Beringin
Kecamatan Alalak Kabupaten Barito Kuala Kalimantan Selatan. Perusahaan bergerak dalam bidang industri kayu lapis dan kayu olahan lainnya, dengan produksi berupa plywood, doorskin, blockboard (papan block), wood working berupa komponen set, dan fancy/parquet flooring (lantai papan untuk dekoratif). PT Tanjung Selatan Makmur Jaya berdiri tanggal 15 Juni 1981 di Jakarta dengan notaries $\mathrm{Ny}$. Darwani Sidi Bakaroeddin, SH. Perusahaan mulai melakukan produksi komersil pada pertengan tahun 1983. Orientasi produksi perusahaan adalah $80 \%$ untuk ekspor, khusus untuk produksi kayu lapis adalah $80 \%$ merupakan kayu lapis mutu tinggi (doorskin) yang $100 \%$ untuk di ekspor khususnya ke Amerika Serikat ( $\pm 50 \%)$, Jepang dan Eropa.

Hubungan karyawan dengan pimpinan baik, karena pimpinan dapat berkomunikasi dengan baik dengan para karyawannya serta mau menerima aspirasi dari karyawan. Dengan adanya 
hubungan yang baik ini maka diharapkan lingkungan kerja menjadi kondusif.

Sementara berdasarkan survei awal dari hasil wawancara dengan manajer PT Tanjung Selatan Makmur Jaya diketahui bahwa kondisi kinerja karyawan masih rendah. Hal ini dapat dibuktikan dengan realisasi produksi selama periode November 2012 sampai dengan September 2013 masih lebih rendah dibandingkan kapasitas izin yang dimiliki PT Tanjung Selatan Makmur Jaya.

Tujuan penelitian ini adalah untuk menguji pengaruh membuktikan secara empiris pengaruh motivasi kerja secara parsial terhadap kinerja karyawan, membuktikan secara empiris pengaruh motivasi kerja secara parsial terhadap kinerja karyawan, membuktikan secara empiris pengaruh motivasi kerja dan lingkungan kerja secara simultan terhadap kinerja karyawan PT Tanjung Selatan Makmur Jaya Kalimantan Selatan.

\section{TINJAUAN TEORITIS}

\section{Motivasi Kerja}

Motivasi berasal dari kata latin movere yang berarti dorongan atau daya penggerak. "Motivasi adalah daya pendorong yang mengakibatkan seseorang anggota organisasi mau dan rela untuk mengerahkan kemampuan dalam bentuk keahlian atau ketrampilan tenaga dan waktunya untuk menyelenggarakan berbagai kegiatan yang menjadi tanggung jawabnya dan melaksanakan kewajibannya, dalam rangka pencapaian tujuan dan berbagai sasaran organisasi yang telah ditentukan sebelumnya" (Siagian, 2003: 138). Berdasarkan paparan teori ini disebutkan bahwa motivasi adalah suatu dorongan yang membuat seorang karyawan itu mampu dan rela untuk mengerahkan kemampuannya untuk organisasi dalam mencapai tujuan.

\section{Lingkungan Kerja}

Menurut As'ad (2001: 50) Terdapat dua faktor yang mempengaruhi 
kinerja, yaitu faktor individu dan faktor situasional. Dalam faktor situasional terdapat faktor fisik dan faktor sosial organisasi yang mempengaruhi pekerjaan. Faktor fisik disini berupa lingkungan dalam organisasi yaitu tata ruang, penerangan, temperatur, sirkulasi udara, kebersihan dan lain-lain. Sedangkan untuk faktor sosial organisasi yang tidak kalah penting adalah faktor lingkungan sosial, dalam hal ini berupa hubungan antara karyawan dengan karyawan lainnya maupun hubungan antara karyawan dengan atasannya.

\section{Kinerja}

“Kinerja dalam bahasa latin berasal dari kata job performance atau performance yang mempunyai arti prestasi kerja atau prestasi sesungguhnya yang dicapai oleh seseorang" (Mangkunegara, 2008:

67). Biasanya orang yang kinerjanya tinggi disebut orang yang produktif dan sebaliknya orang yang tingkat kinerjanya tidak mencapai tingkat standar dikatakan sebagai orang yang tidak produktif atau berperforma rendah.

\section{Penelitian Terdahulu}

Firnidia (2008) dalam penelitiannya yang berjudul "Pengaruh Motivasi Terhadap Kinerja Pegawai Dinas Pendidikan dan Kebudayaan Kabupaten Jepara" meneliti pengaruh motivasi terhadap kinerja. Hasil penelitian menunjukkan adanya pengaruh positif motivasi terhadap kinerja pegawai dengan koefisien determinasi sebesar 31,3\%. Hal ini berarti kinerja pegawai 31,3\% dipengaruhi oleh motivasi dan sisanya $(69,7 \%)$ dipengaruhi oleh faktor lainnya.

Selain itu penelitian yang dilakukan oleh Noviani (2009) dengan judul "Pengaruh Lingkungan Kerja Terhadap Kinerja Karyawan Bagian Produksi PT Glory Industrial Semarang II" meneliti tentang pengaruh lingkungan kerja terhadap kinerja karyawan. Hasil penelitian menunjukkan bahwa terdapat pengaruh positif lingkungan kerja terhadap kinerja karyawan dengan koefisien 
determinasi sebesar 18,49\%. Hal ini berarti motivasi karyawan 18,49\% dipengaruhi oleh lingkungan kerja, dan sisanya $(71,51 \%)$ dipengaruhi oleh faktor lainnya.

Penelitian ini mengacu pada penelitian yang dilakukan oleh Asriyanto (2013) dengan judul “Pengaruh Motivasi Kerja dan Lingkungan Kerja Terhadap Kinerja Karyawan CV Kalika Intergraha di Semarang". Hasil penelitian menunjukkan pengaruh motivasi kerja sebesar $17,7 \%$ terhadap kinerja dan lingkungan kerja berpengaruh sebesar $12,4 \%$ terhadap kinerja. Secara simultan besarnya pengaruh motivasi kerja, dan lingkungan kerja terhadap kinerja adalah sebesar $43,8 \%$.

\section{Kerangka Berpikir}

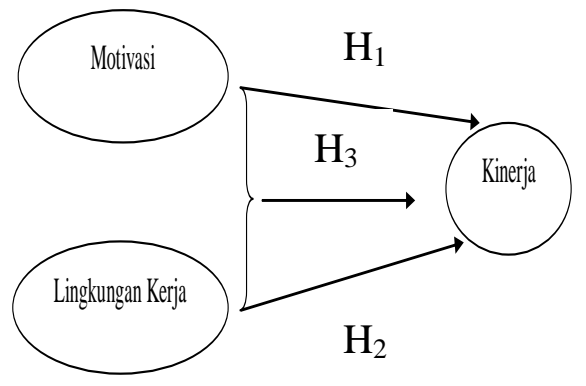

Gambar 1: Kerangka Konseptual

\section{Hipotesis}

Hipotesis dalam penelitian ini adalah sebagai berikut :

H1 : Terdapat pengaruh motivasi kerja terhadap kinerja karyawan secara parsial pada PT Tanjung Selatan Makmur Jaya.

H2 : Terdapat pengaruh lingkungan kerja terhadap kinerja karyawan secara parsial pada PT Tanjung Selatan Makmur Jaya.

H3 : Terdapat pengaruh motivasi kerja dan lingkungan kerja terhadap kinerja karyawan secara simultan pada PT Tanjung Selatan Makmur Jaya.

\section{METODE PENELITIAN}

Penelitian ini merupakan penelitian kuantitatif yang bertujuan untuk menguji hipotesis. Penelitian ini didesain menggunakan metode survey yaitu dengan membagikan kuesioner kepada para responden yang merupakan karyawan tetap PT Tanjung Selatan Makmur Jaya. 
Tempat penelitian di PT Tanjung Selatan Makmur Jaya ,Jl.Poros Trans Banjarmasin - Pangkaraya,dekat Jembatan Barito,Banjarmasin Kalimantan Selatan,Waktu penelitian 3 ( tiga ) bulan. Populasi dalam penelitian ini adalah seluruh karyawan tetap PT Tanjung Selatan Makmur Jaya di Wilayah Kalimantan Selatan ( Banjarmasin ),sampel yang diambil dengan teknik rumus Slovin sebesar 67 dari 207 jumlah karyawan tetap PT Tanjung Selatan Makmur Jaya.

Data penelitian diolah dan dianalisis dengan menggunakan uji statistik regresi linear berganda dengan menggunakan software SPSS for windows versi 20 .

\section{HASIL PENELITIAN DAN}

\section{PEMBAHASAN}

\section{Statistik Deskriptif Responden}

Responden terdiri dari 33 orang lakilaki $(49,25 \%)$ dan 34 orang perempuan $(50,75 \%)$ dari total 67 orang responden. Hal ini dilakukan untuk persamaan gender dan hasil yang lebih objektif tidak memihak ke jenis kelamin tertentu.

Berdasarkan usia bahwa 17 orang responden berusia $<30$ tahun (25,37\%), 35 orang berusia antara 31 - 40 tahun (52,24\%), dan yang di atas 40 tahun sebanyak 15 orang $(22,39 \%)$, Hal ini dilakukan karena presentasi usia yang $30-40$ tahun merupakan karyawan senior serta bisa lebih ojektif dalam melakukan penjawaban kuisioner .

Berdasarkan masa kerja bahwa 10 orang responden bekerja kurang dari 5 tahun $(14,93 \%), 46$ orang bekerja antara 6 - 10 tahun $(47,76 \%)$, dan yang lebih dari 10 tahun sebanyak 20 orang $(37,31 \%)$, Hal ini menunjukkan usia bekerja $5-10$ tahun merupakan karyawan lama dengan hasil pekerjaan yang baik Tingkat pendidikan responden bahwa 10 orang responden lulusan Sekolah Dasar (14,93 \%), 6 orang responden lulusan SMP (8,96\%), 36 orang responden lulusan SMA $(53,73 \%)$ dan 15 orang responden lulusan S1 $\quad(22,36 \%), \mathrm{Hal} \quad$ ini menjelaskan bahwa yang presentasi 
paling besar pendidikan SMA karena sesuai proses rekrutment manajemen memudahkan kualitas yang segar agar kedepan dalam pengembangan akan menjadi lebih mudah.

Berdasarkan hasil uji validitas di atas terlihat nilai communality > 0,6 berarti data yang diuji valid (dapat dipercaya), kecuali untuk pertanyaan LK1 dan LK3. Berarti hanya pertanyaan LK2, LK4, LK5,

LK7, LK8, LK9, dan LK10 yang

dapat diuji asumsi klasik dan regresi.

\section{Uji Reliabilitas}

Berdasarkan uji reliabilitas di atas terlihat nilai Cronbach Alpha > 0,6 berarti data yang diperoleh reliabel (handal).

\section{Uji Statistik $\mathbf{t}$}

Coefficients

\begin{tabular}{|c|c|c|c|c|c|c|}
\hline \multirow[b]{2}{*}{ Model } & & \multicolumn{2}{|c|}{$\begin{array}{c}\text { Unstandardized } \\
\text { Coefficients }\end{array}$} & \multirow{2}{*}{$\begin{array}{c}\text { Standardized } \\
\text { Coefficients } \\
\text { Beta } \\
\end{array}$} & \multirow[b]{2}{*}{$?$} & \multirow[b]{2}{*}{ Sig. } \\
\hline & & B & Std. Error & & & \\
\hline 1 & (Constant) & -12.232 & 4.410 & & -2.774 & .007 \\
\hline & M & .863 & .050 & .843 & 17.182 & .000 \\
\hline & LK & .795 & .081 & .480 & 9.785 & .000 \\
\hline
\end{tabular}

a. Dependent Variable: $\mathrm{K}$

Data Primer : Diolah November,2015 Hasil pengujian di atas memperlihatkan nilai signifikansi untuk pengaruh motivasi terhadap kinerja sebesar 0,000 <0,05. Hal ini berarti hipotesis 1 bahwa motivasi berpengaruh secara parsial terhadap kinerja PT Tanjung Selatan Makmur Jaya terbukti, maka hipotesis 1 diterima.

Sementara nilai signifikansi untuk pengaruh lingkungan kerja terhadap kinerja sebesar 0,000 <0,05. Hal ini berarti hipotesis 2 yang menyatakan lingkungan kerja berpengaruh secara parsial terhadap kinerja PT Tanjung Selatan Makmur Jaya terbukti, maka hipotesis 2 diterima.

\section{Uji Statistik F}

\section{$\operatorname{ANOVA}(b)$}

\begin{tabular}{|c|c|c|c|c|c|c|}
\hline Model & & $\begin{array}{l}\text { Sum of } \\
\text { Squares }\end{array}$ & Df & Mean Square & $F$ & Sig. \\
\hline \multirow[t]{3}{*}{1} & Regression & 297.145 & 2 & 148.573 & 178.391 & $.000(a)$ \\
\hline & Residual & 53.302 & 64 & .833 & & \\
\hline & Total & 350.448 & 66 & & & \\
\hline
\end{tabular}

a Predictors: (Constant), LK, M

b Dependent Variable: K

Data Primer : Diolah November,2015 Hasil Uji F di atas menunjukkan nilai signifikansi sebesar 0,000 $<0,05$. Hal ini berarti bahwa hipotesis 3 yang menyatakan motivasi dan lingkungan kerja secara simultan berpengaruh terhadap kinerja 
karyawan PT Tanjung Selatan Pendidikan dan Kebudayaan

Makmur Jaya terbukti, maka Kabupaten Jepara. Penelitian hipotesis 3 diterima.

Asriyanto (2013) menunjukkan bahwa motivasi secara parsial

Uji Koefisien Determinasi Model Summary

\begin{tabular}{|l|r|r|r|r|r|}
\hline Model & \multicolumn{1}{|c|}{ R } & R Square & $\begin{array}{r}\text { Adjusted } \\
\text { R Square }\end{array}$ & $\begin{array}{r}\text { Std. Error of } \\
\text { the Estimate }\end{array}$ & $\begin{array}{l}\text { Durbin- } \\
\text { Watson }\end{array}$ \\
\hline 1 & $.788^{\mathrm{a}}$ & .620 & .615 & 1.43068 & 2.526 \\
\hline
\end{tabular}

a. Predictors: (Constant), M

b. Dependent Variable: $K$

Data Primer : Diolah November,2015

Berdasarkan tabel di atas terlihat nilai Adjusted $R^{2}$ sebesar 0,615 . Hal ini menunjukkan bahwa secara parsial motivasi berpengaruh sebesar $61,50 \%$ terhadap kinerja pada PT Tanjung Selatan Makmur Jaya sedangkan 38,50\% dipengaruhi oleh variabel lainnya yang tidak diteliti dalam penelitian ini. Hasil penelitian ini membuktikan bahwa di PT Tanjung Selatan Makmur Jaya motivasi memiliki pengaruh yang sangat besar terhadap kinerja dibandingkan dengan penelitianpenelitian sebelumnya. Penelitian Firnidia (2008) menunjukkan bahwa motivasi berpengaruh sebesar $31,3 \%$ terhadap kinerja Pegawai Dinas berpengaruh sebesar 17,7\% terhadap kinerja Karyawan CV Kalika Integraha Semarang (Tabel 2.1). Oleh karena itu pimpinan PT Tanjung Selatan Makmur Jaya Kalimantan Selatan harus selalu memingkatkan motivasi kerja karyawan dengan cara meningkatkan bonus dan intensif bagi karyawan yang memiliki prestasi secara adil.

\section{Uji Koefisien Determinasi} Hipotesis $2\left(\mathrm{R}^{2}\right)$.

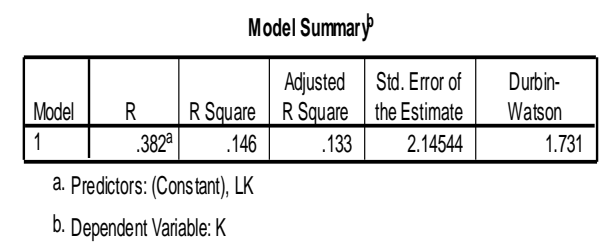

Data Primer : Diolah November,2015 Tabel di atas menunjukkan pengaruh lingkungan kerja secara parsial terhadap kinerja karyawan PT Tanjung Selatan Makmur Jaya sebesar $13,3 \%$ sedangkan $86,7 \%$ dipengaruhi oleh variabel lainnya yang tidak diteliti dalam penelitian 
ini. Hal ini membuktikan bahwa pengaruh motivasi terhadap kinerja karyawan lebih besar dibandingkan lingkungan kerja. Pengaruh lingkungan kerja terhadap kinerja karyawan di PT Tanjung Selatan Makmur Jaya lebih rendah dibandingkan dengan penelitian Noviani (2009) yang membuktikan bahwa lingkungan kerja secara parsial memiliki pengaruh sebesar 18,49\% terhadap kinerja karyawan PT Glory Industrial Semarang II. Akan tetapi pengaruh lingkungan kerja terhadap kinerja karyawan di PT Tanjung Selatan Makmur Jaya lebih besar dibandingkan hasil penelitian Asriyanto (2013) yang membuktikan pengaruh lingkungan kerja secara parsial terhadap kinerja karyawan CV Kalika Integraha Semarang sebesar 12,4\% (Tabel 2.1).

\section{Uji Koefisien Determinasi}

Hipotesis 3 ( $\left.R^{2}\right)$.

Model Summary(b)

\begin{tabular}{|l|r|r|r|r|r|}
\hline Model & R & R Square & $\begin{array}{l}\text { Adjusted R } \\
\text { Square }\end{array}$ & $\begin{array}{l}\text { Std. Error of } \\
\text { the Estimate }\end{array}$ & Durbin-Watson \\
\hline 1 & $.921(\mathrm{a})$ & .848 & .843 & .91261 & 2.146 \\
\hline
\end{tabular}

a Predictors: (Constant), LK, M

b Dependent Variable: K
Data Primer : Diolah November,2015 Berdasarkan tabel di atas terlihat nilai Adjusted $R^{2}$ sebesar 0,843 Hal ini membuktikan bahwa motivasi dan lingkungan kerja secara simultan memiliki pengaruh yang besar terhadap kinerja karyawan PT Tanjung Selatan Makmur Jaya yaitu sebesar $84,30 \%$ sementara $15,70 \%$ dipengaruhi oleh variabel lainnya yang tidak diteliti dalam penelitian ini.

Hasil penelitian ini menunjukkan pengaruh motivasi dan lingkungan kerja secara simultan terhadap kinerja karyawan PT Tanjung Selatan Makmur Jaya lebih besar daripada penelitian Asriyanto (2013) yang membuktikan pengaruh motivasi dan lingkungan kerja secara simultan terhadap kinerja karyawan CV.Kalika Integraha Semarang sebesar $43,8 \%$.

\section{KESIMPULAN}

Kesimpulan dari penelitian ini adalah :

1. Nilai signifikansi untuk pengaruh motivasi terhadap 
kinerja sebesar 0,000<0,05. Hal ini berarti hipotesis 1 bahwa motivasi berpengaruh secara parsial terhadap kinerja PT Tanjung Selatan Makmur Jaya terbukti, maka hipotesis 1 diterima. Motivasi memiliki pengaruh sebesar $61,50 \%$ terhadap kinerja karyawan PT Tanjung Selatan Makmur Jaya Kalimantan Selatan,sesuai dengan penelitian terdahulu oleh Linda

Firnidia,2008.Dimana

manajemen perusahaan perlu meningkatkan lagi motivasi terhadap karyawannya bisa dalam bentuk

pelatihan,penghargaan bagi yang berprestasi .

2. Nilai signifikansi untuk pengaruh lingkungan kerja terhadap kinerja sebesar $0,000<0,05$. Hal ini berarti hipotesis 2 bahwa lingkungan kerja berpengaruh secara parsial terhadap kinerja PT Tanjung Selatan Makmur Jaya terbukti, maka hipotesis 2 diterima. Lingkungan kerja memiliki pengaruh sebesar $13,30 \%$ terhadap kinerja karyawan PT Tanjung Selatan Makmur Jaya Kalimantan Selatan,sesuai dengan peneltian terdahulu oleh Sari Emilia Noviani,2009.Dimana hal ini penting lingkungan kerja yang tertata rapi akan berdampak pada produktivitas kinerja karyawan meningkat maupun kenyamanan bekerja.

3. Nilai signifikansi untuk pengaruh motivasi dan lingkungan kerja terhadap kinerja sebesar 0,000 0,05 yang berarti hipotesis 3 bahwa motivasi dan lingkungan kerja seara simultan berpengaruh terhadap kinerja karyawan PT Tanjung Selatan Makmur 
Jaya diterima. Motivasi dan lingkungan kerja secara simultan berpengaruh sebesar $\quad 84,30 \% \quad$ erhadap kinerja karyawan PT Tanjung Selatan Makmur Jaya Kalimantan Selatan,hal ini sesuai dengan penelitian terdahulu oleh Gardjito,dkk,.2004 dan Asriyanto,Nur

Abib,2013.Dimana hal ini menjadi dasar untuk diteruskan bahwa selain memotivasi karyawan juga harus memperhatikan kondisi lingkungan kerja yang nyaman dimana berdampak global pada kinerja karyawan yang berada disana .

\section{SARAN}

Berdasarkan kesimpulan di atas dapat disarankan bahwa:

1.Untuk memperbaiki kinerja karyawan dapat dilakukan dengan cara meningkatkan motivasi dan lingkungan kerja PT Tanjung Selatan Makmur Jaya secara bertahap .

2.Untuk meningkatkan motivasi dilakukan dengan cara memberikan intensif dan bonus yang sesuai dengan prestasi kerja karyawan.

3.Untuk lingkungan kerja dapat diperbaiki dengan meningkatkan kualitas hubungan antara karyawan dan pimpinan perusahaan, maupun dengan sesama karyawan.

\section{DAFTAR PUSTAKA}

Ahyari, Agus, 2006. Manajemen Produksi dan Pengendalian Produksi. Yogyakarta: BPFE Asriyanto, Nur Abib, 2013. Pengaruh Motivasi Kerja dan Lingkungan Kerja Terhadap Kinerja Karyawan CV Kalika Intergraha di Semarang. Tesis

Arikunto, Suharsimi, 2002. Prosedur Penelitian, Suatu Pendekatan Praktek. Jakarta: PT Rineka Cipta

Cushway, Barry dan Lodge, Derek, 1995. Organizational Behaviour and Design. Jakarta: Elex Media Komputindo 
Hammed, T Ayo dan Shadare, Oluseyi A, 2009. Influence of Work Motivation, Leadership,Effectiveness and Time Management on Employees's Performance in Some Selected Industries in Ibadan, Oyo State, Nigeria.

Handoko, T Hani, 2001. Manajemen Personalia dan Sumber Daya Manusia. Yogyakarta: BPFE Hasibuan, Malayu, S.P., 2002. Manajemen Sumer Daya Manusia. Jakarta: PT bumi Aksara

Linda, Firnidia, 2008. Pengaruh Motivasi Terhadap Kinerja Pegawai Dinas Pendidikan dan Kebudayaan Kabupaten Jepara. Thesis

Mathis, Robert. L dan Jackson, John. H., 2006. Human Resources Management. Edisi Kesepuluh. Jakarta: salemba Empat .

Mangkunegara, Anwar Prabu AA, 2006. Perencanaan dan Pengembangan SDM. Bandung: PT Refika Aditama Noviani, Sari Emilia, 2009. Pengaruh Lingkungan Kerja Terhadap Kinerja Karyawan Bagian Produksi PT Glory Industrial Semarang II. Tesis

Robbins, Stephen P, 2003. Perilaku Organisasi. Jilid 2. Jakarta: PT Indeks

Siagian, Sondang P, 2007. Manajemen Sumber Daya Manusia. Jakarta: PT Bumi Aksara

Simamora, Henry, 1997. Manajemen Sumber Daya Manusia. Yogyakarta: STIE YKPN
Timpe, A. Dale, 1999. Seri Manajemen Sumber Daya Manusia. Jakarta: Gramedia

Wahjosumidjo, 1994. Kepemimpinan dan Motivasi. Jakarta: Ghalia Indonesia 